\title{
Controle de mosca-branca com extratos vegetais, em tomateiro cultivado em casa-de-vegetação
}

\author{
Edson LL Baldin ${ }^{1}$; Douglas R Souza ${ }^{2}$; Efrain S Souza ${ }^{2}$; Ronaldo A Beneduzzi ${ }^{2}$ \\ ${ }^{1}$ UNESP/FCA, Depto. Produção Vegetal, Defesa Fitossanitária, C. postal 237, 18610-307 Botucatu-SP; ${ }^{2}$ UNICASTELO/FCA, Lab. \\ Entomologia, C. postal 221, 15600-000 Fernandópolis-SP; elbaldin@fca.unesp.br
}

\section{RESUMO}

Visando buscar métodos alternativos no controle da mosca-branca Bemisia tabaci (Gennadius) biótipo B em tomateiro, foram realizados testes de atratividade e preferência para oviposição em casade-vegetação, utilizando-se quatorze extratos aquosos a 3\% (peso/ volume). Os extratos foram preparados com partes de Azadirachta indica, Trichilia pallida, Chenopodium ambrosioides, Piper nigrum, Melia azedarach, Ruta graveolens, Ricinus communis, Mentha pulegium, Tagetes erecta, Eucalyptus citriodora, Cymbopogon nardus e Coriandrum sativum. Numa segunda etapa, os extratos mais eficientes em casa-de-vegetação foram observados em laboratório, a fim de avaliar o possível efeito sistêmico dos mesmos sobre ninfas da mosca-branca. Constatou-se que as plantas de tomateiro pulverizadas com extratos à base de folhas de $M$. pulegium e folhas e sementes de $A$. indica foram menos atrativas aos adultos do inseto. Plantas pulverizadas com extratos de folhas de A. indica e folhas + ramos de $R$. communis mostraram efeitos deterrentes à oviposição do inseto, reduzindo o número de ovos; em contrapartida, o extrato à base de folhas de $C$. nardus estimulou a oviposição da moscabranca sobre as plantas. $\mathrm{O}$ uso dos extratos por via sistêmica não afetou o período de desenvolvimento (ovo-adulto) da mosca-branca; entretanto, a presença de extratos de sementes e folhas de $A$. indica e de folhas de $M$. pulegium provocou aumento significativo na mortalidade de ninfas de B. tabaci biótipo B.

Palavras-chave: Bemisia tabaci biótipo B, Lycopersicon esculentum, plantas inseticidas, atratividade, deterrência, efeito sistêmico.

\section{ABSTRACT}

Use of plant extracts on whitefly control in tomato grown in greenhouse

Looking for alternative methods of control to silverleaf whitefly Bemisia tabaci (Gennadius) biotype B in tomato, attractiveness and oviposition preference tests were accomplished in greenhouse using fourteen aqueous extracts at $3 \%$ (weight/volume). The extracts were prepared with parts from Azadirachta indica, Trichilia pallida, Chenopodium ambrosioides, Piper nigrum, Melia azedarach, Ruta graveolens, Ricinus communis, Mentha pulegium, Tagetes erecta, Eucalyptus citriodora, Cymbopogon nardus and Coriandrum sativum. The most efficient extracts in greenhouse were also tested in laboratory to evaluate the possible systemic effect on whitefly nymphs. Tomato plants sprayed with extracts of leaves from $M$. pulegium, leaves and seeds from $A$. indica were less attractive to the adults of the insect. Plants sprayed with extracts of leaves from $A$. indica and leaves + branches from $R$. communis showed deterrent effects on the insect oviposition, reducing the number of eggs; in an opposite way, the extract of leaves from $C$. nardus stimulated the whitefly oviposition on the plants. The use of extracts in a systemic way did not affect the whitefly development period (egg-adult). The extracts of seeds and leaves from A. indica and leaves from $M$. pulegium increased the mortality of nymphs of B. tabaci biotype B.

Keywords: Bemisia tabaci biotype B, Lycopersicon esculentum, botanical insecticides, attractiveness, deterrence, systemic effect.

\section{(Recebido para publicação em 24 de abril de 2007; aceito em 27 de novembro de 2007)}

$\mathrm{O}$ tomate vem sendo extensivamente cultivado na América há séculos, acreditando-se que tenha se originado ao Norte da América do Sul (Polston \& Anderson, 1999). O Brasil destaca-se em oitavo lugar na produção mundial e em sétimo no processamento dessa hortaliça (Camargo Filho, 2001). A produtividade do tomate poderia ser maior, não fosse a elevada suscetibilidade da cultura a microrganismos e insetos (Lopes et al., 2000; França et al., 2000).

A mosca-branca, Bemisia tabaci (Genn.) biótipo B, é atualmente apontada como uma das principais pragas do tomateiro e seu controle é dificultado pelo seu hábito de permanecer na fase abaxial das folhas (Villas Bôas et al.,
1997) e também pela facilidade com que desenvolve resistência a ingredientes ativos (Prabhaker et al., 1999). Além disso, o biótipo B é o mais freqüente em solanáceas, cucurbitáceas e ornamentais (Oliveira \& Silva, 1997).

Esse inseto pode ocasionar perdas de até $100 \%$ na produção de tomate, sendo que os danos diretos são provocados pela sucção de seiva da região do floema e ação toxicogênica, resultando em amarelecimento irregular dos frutos e alterações na consistência da polpa (Carneiro et al., 1999; Gallo et al., 2002). Os danos indiretos estão relacionados à transmissão de geminivírus, que causam amarelecimento e nanismo das plantas, além de enrugamento das folhas terminais (Villas Bôas et al., 1997; Faria et al., 1997; Matos et al., 2003).

Até o presente momento, o controle químico através da pulverização com inseticidas sintéticos, é o método mais empregado no combate à mosca-branca em tomateiro. Entretanto, devido à necessidade de redução do volume de resíduos químicos nas lavouras, métodos alternativos de controle como o uso de extratos vegetais com atividades inseticida e/ou insetistática têm revelado resultados promissores no combate à $B$. tabaci biótipo B (Souza \& Vendramim, 2000, 2001; Cunha et al., 2005; Bogorni $\&$ Vendramim, 2005). Porém, cabe ressaltar que a maioria desses estudos teve como enfoque avaliar a ação de contato dos extratos, sem contudo observar a possível atividade sistêmica dos mate- 
riais, aspecto também abordado no presente trabalho.

Tendo em vista os riscos que envolvem o uso de inseticidas convencionais, principalmente aqueles associados à saúde do homem, à poluição e ao desenvolvimento de resistência às formulações sintéticas por parte dos insetos, o presente trabalho teve por objetivo avaliar a utilização de extratos botânicos sobre a mosca-branca $B$. tabaci biótipo B, através de testes de atratividade, preferência para oviposição e atividade inseticida via sistema radicular.

\section{MATERIAL E MÉTODOS}

O trabalho foi conduzido em casade-vegetação e laboratório entre 2005 e 2006. Na primeira fase avaliou-se a atratividade de plantas de tomateiro pulverizadas com extratos vegetais e a deterrência na oviposição de $B$. tabaci biótipo B. Na segunda fase foi estudado o efeito inseticida dos extratos vegetais via sistêmica sobre ninfas da mosca-branca.

Criação estoque de B. tabaci biótipo B - A fim de se manter uma criação de B. tabaci biótipo B que oferecesse insetos em número suficiente para o desenvolvimento do trabalho, uma população inicial do inseto foi trazida do Setor de Entomologia do IAC. Posteriormente a criação foi estabelecida em uma gaiola metálica de 2,0 x 2,5 x 2,0 m, com teto coberto por plástico e sombrite e as laterais revestidas por tela anti-afídeo branca. Para a manutenção da criação, no interior da gaiola foram acomodados vasos $(20 \mathrm{~L})$ contendo plantas de soja, couve-manteiga, abóbora e poinsetia. Os vasos foram monitorados semanalmente e as plantas deterioradas substituídas por outras sadias.

Obtenção de extratos vegetais Para o preparo dos quatorze extratos utilizados nos testes foram coletadas as seguintes estruturas vegetais: folhas e sementes de nim (Azadirachta indica A. Juss.); folhas e ramos de catiguá (Trichilia pallida Swartz); folhas + ramos + inflorescências de erva-de-Santa-Maria (Chenopodium ambrosioides L.); sementes de pimenta-do-reino
(Piper nigrum L.); folhas + ramos de cinamomo (Melia azedarach L.); folhas de arruda (Ruta graveolens L.); folhas + ramos de mamona (Ricinus communis L.); folhas de poejo (Mentha pulegium L.); folhas + ramos de cravo-de-defunto (Tagetes erecta L.); folhas de eucalipto (Eucalyptus citriodora Hook); folhas de citronela (Cymbopogon nardus L.) e folhas de coentro (Coriandrum sativum L.). Com exceção das folhas e ramos provenientes de $T$. pallida, que foram coletadas na ESALQ/USP, as demais estruturas vegetais utilizadas na confecção dos extratos foram coletadas no Setor de Plantas Medicinais e Fazenda Experimental da FCA/ UNICASTELO de Fernandópolis, durante o mês de setembro de 2005, sempre no período da manhã. Os materiais coletados foram secos em estufa com circulação de ar a $40^{\circ} \mathrm{C}$ por $48 \mathrm{~h}$ e posteriormente triturados em moinho elétrico de facas até a obtenção dos pós, os quais foram armazenados separadamente por espécie e estrutura vegetal em recipientes escuros, hermeticamente fechados. Os extratos foram preparados misturando-se, com o auxílio de um agitador, $3 \mathrm{~g}$ de pó de cada material a $100 \mathrm{~mL}$ de água destilada (Souza \& Vendramim, 2000, 2001). As suspensões resultantes foram mantidas à temperatura ambiente e sob agitação por $24 \mathrm{~h}$, visando a extração dos compostos hidrosolúveis. Após isso, as soluções foram filtradas em tecido voil (5 camadas), originando os extratos aquosos a 3,0\% (peso/volume).

Atratividade e preferência para oviposição - A fim de se avaliar a atratividade e a oviposição de $B$. tabaci biótipo $\mathrm{B}$ em plantas de tomateiro pulverizadas com extratos vegetais, foi realizado um teste em condições de livre escolha, efetuando-se seis repetições em delineamento de blocos casualizados. Para tanto, o genótipo de tomateiro IACSanta Clara foi semeado em bandeja de polietileno expandido e, após 28 dias da emergência, as plântulas foram transplantadas para vasos de $2 \mathrm{~L}$ de capacidade, recebendo tratos culturais e adubação recomendados para a cultura (Raij et al., 1997).

Doze dias após o transplante e com auxílio de borrifador manual (200 mL), as plantas foram pulverizadas com os respectivos extratos até o ponto de escorrimento. Após 15 minutos da aplicação, os vasos com as plantas de tomateiro foram distribuídos de forma aleatória, em círculo, no interior de gaiolas idênticas à utilizada na criação da mosca-branca. Em seguida, liberou-se no chão, e ao centro das gaiolas, uma proporção de 100 adultos não sexados da mosca-branca por vaso (totalizando 1.400 insetos por gaiola).

A atratividade foi avaliada 24 e 48 horas após a liberação dos insetos, contando-se, com o auxílio de um espelho, o número de adultos presentes na superfície abaxial de três folíolos previamente marcados nos terços superior, médio e inferior das plantas.

Para se determinar a preferência para oviposição, após a segunda contagem (48 h) do número de adultos, outros três folíolos previamente marcados (terços superior, médio e inferior) foram retirados das plantas e conduzidos ao laboratório, onde, com o auxílio de microscópio estereoscópico, foi contado o número de ovos $/ \mathrm{cm}^{2}$ na página abaxial de cada um deles. Calculou-se também um índice de preferência para oviposição: IPO $=[(\mathrm{T}-\mathrm{P}) /(\mathrm{T}+\mathrm{P})] \times 100$, onde $\mathrm{T}=\mathrm{n}^{\circ} \mathrm{de}$ ovos contados no tratamento avaliado (extrato) e $\mathrm{P}=\mathrm{n}^{\circ}$ de ovos contados no tratamento padrão, água destilada. $\mathrm{O}$ índice varia de +100 (muito estimulante) até -100 (total deterrência), sendo o valor 0 indicativo de neutralidade. A classificação dos extratos foi feita a partir da comparação das médias de ovos dos tratamentos com a média do tratamento água destilada, levando-se em consideração o erro padrão da média do ensaio para a diferenciação dos mesmos (Baldin et al., 2000, 2005).

Avaliação do efeito sistêmico via aplicação no solo - Uma vez que alguns dos extratos vegetais empregados no presente trabalho possuem ação inseticida de contato comprovada contra ovos e ninfas de mosca-branca (Souza \& Vendramim, 2001), foi realizado um ensaio em sala climatizada $\left(\mathrm{T}=25 \pm 2^{\circ} \mathrm{C}\right.$; $\mathrm{UR}=70 \pm 10 \%$ e fotofase $=12 \mathrm{~h}$ ) visando verificar a possível ação sistêmica desses extratos. Nesse caso, porém, foram avaliados apenas os extratos provenientes de folhas e de sementes de $A$. 
indica, de folhas de $M$. pulegium e de folhas + ramos de $R$. communis, já que foram mais eficientes nos testes de atratividade e deterrência para oviposição e também levando-se em consideração a disponibilidade desses materiais.

O genótipo IAC-Santa Clara foi novamente cultivado em vasos $(2 \mathrm{~L}) \mathrm{e}$ quando as plantas estavam com 35 dias de idade, três vasos por tratamento foram separados. Três folíolos de cada planta (terços superior, médio e inferior) foram individualizados, acoplando-se pequenas gaiolas $(15 \times 8 \mathrm{~cm})$ confeccionadas em tecido "voil" e liberando-se no interior de cada uma delas 50 adultos não sexados do inseto. A infestação foi mantida por $24 \mathrm{~h}$ e, após isso, os insetos foram retirados, mantendo-se 30 ovos viáveis/folíolo, onde cada folíolo representou uma repetição, contendo 30 parcelas. Três dias após a eclosão das ninfas, o solo seco próximo ao colo das plantas foi irrigado uma única vez com $50 \mathrm{~mL}$ dos extratos a $1 \%(\mathrm{p} / \mathrm{v})$ e com água destilada (testemunha), conforme empregado por Souza \& Vendramim (2005). Durante o teste as plantas foram também irrigadas a cada dois dias com $100 \mathrm{~mL}$ de água, a fim de suprir suas necessidades fisiológicas. As observações foram diárias e no mesmo horário, avaliando-se o período de desenvolvimento de ovo a adulto e a mortalidade total na fase imatura. $\mathrm{O}$ experimento foi realizado em delineamento inteiramente casualizado, com cinco tratamentos (quatro extratos e água destilada), efetuando-se nove repetições (três vasos por extrato).

Os dados obtidos foram submetidos à análise de variância, sendo as médias comparadas pelo teste de Tukey, ao nível de 5\% de probabilidade. Quando necessário, os dados originais (x) foram transformados em $(\mathrm{x}+0,5)^{1 / 2} \mathrm{e}$ arc sen $(\mathrm{x}+0,5)^{1 / 2}$.

\section{RESULTADOS E DISCUSSÃO}

Analisando-se o número de adultos da mosca-branca atraídos por folíolos de tomateiro após 24 horas da aplicação de extratos vegetais (Tabela 1), nota-se que,

Tabela 1. Número médio ( \pm EP) de adultos de B. tabaci biótipo B contados em folíolos de tomateiro, 24 e 48 horas após a aplicação de diferentes extratos vegetais (average number of adults of $B$. tabaci biotype B on tomato leaflets, 24 and 48 hours after the application of various vegetable extracts). Botucatu, UNESP, 2006.

\begin{tabular}{lcc}
\hline \multirow{2}{*}{ Extrato $^{1}$} & \multicolumn{2}{c}{$\mathbf{N}^{\circ}$ de adultos $^{2}$} \\
\cline { 2 - 3 } & $\mathbf{2 4} \mathbf{~ h}$ & $\mathbf{4 8 ~ h}$ \\
\hline Ricinus communis (F+R) & $2,33 \pm 0,18 \mathrm{a}$ & $1,41 \pm 0,26 \mathrm{abc}$ \\
Eucalyptus citriodora (F) & $1,58 \pm 0,08 \mathrm{~b}$ & $1,16 \pm 0,16 \mathrm{abcde}$ \\
Cymbopogon nardus (F) & $1,50 \pm 0,09 \mathrm{~b}$ & $1,91 \pm 0,27 \mathrm{a}$ \\
Chenopodium ambrosioides & $1,50 \pm 0,17 \mathrm{~b}$ & $1,25 \pm 0,16 \mathrm{abcde}$ \\
(F+ R+I) & $1,40 \pm 0,10 \mathrm{~b}$ & $1,35 \pm 0,13 \mathrm{abcd}$ \\
Tajetes erecta (F+ R) & $1,33 \pm 0,16 \mathrm{~b}$ & $0,58 \pm 0,16 \mathrm{def}$ \\
Trichilia pallida (R) & $1,25 \pm 0,14 \mathrm{~b}$ & $0,66 \pm 0,14 \mathrm{cdef}$ \\
Trichilia pallida (F) & $1,17 \pm 0,06 \mathrm{bc}$ & $0,66 \pm 0,14 \mathrm{cdef}$ \\
Piper nigrum (S) & $1,08 \pm 0,06 \mathrm{bc}$ & $1,58 \pm 0,18 \mathrm{ab}$ \\
Água destilada & $0,83 \pm 0,10 \mathrm{bc}$ & $0,91 \pm 0,10 \mathrm{bcdef}$ \\
Ruta graveolens (F) & $0,50 \pm 0,07 \mathrm{bc}$ & $0,58 \pm 0,09 \mathrm{def}$ \\
Melia azedarach (F+R) & $0,50 \pm 0,07 \mathrm{bc}$ & $1,83 \pm 0,13 \mathrm{a}$ \\
Coriandrum sativum (F) & $0,33 \pm 0,05 \mathrm{bc}$ & $0,58 \pm 0,16 \mathrm{def}$ \\
Azadirachta indica (S) & $0,25 \pm 0,04 \mathrm{c}$ & $0,33 \pm 0,07 \mathrm{f}$ \\
Azadirachta indica (F) & $0,17 \pm 0,01 \mathrm{c}$ & $0,50 \pm 0,07 \mathrm{ef}$ \\
Mentha pulegium (F) & $42,66^{*}$ & $10,67^{*}$ \\
\hline F & 6,29 & 10,44 \\
CV (\%) &
\end{tabular}

${ }^{1}$ Legenda: $F=$ folha; $R=$ ramo; $I=$ inflorescência; $S=$ semente; ${ }^{2}$ Dados originais. Para análise estatística foram transformados em $(x+0,5)^{1 / 2}$. Médias seguidas de mesma letra, na coluna não diferem entre si pelo teste de Tukey a $5 \%$ de probabilidade. $\left({ }^{1} \mathrm{~F}=\right.$ leaf; $\mathrm{R}=$ branch; $\mathrm{I}=$ inflorescence; $\mathrm{S}=$ seed. ${ }^{2}$ Original data, transformed in $(\mathrm{x}+0,5)^{1 / 2}$ for statistical analysis. Means followed by the same letter in the column did not differ from each other; Tukey, 5\%).

embora não tenham diferido da testemunha, as plantas pulverizadas com extratos provenientes de folhas de $M$. pulegium e A. indica apresentaram as menores médias de insetos presentes, diferindo das plantas contendo extratos de folhas + ramos de $R$. communis, folhas de E. citriodora, folhas de $C$. nardus, folhas + ramos + inflorescências de $C$. ambrosioides, folhas + ramos de T. erecta e folhas e ramos de T. pallida que se destacaram com as maiores médias. A média de insetos constatada nos folíolos tratados com extrato à base de folhas + ramos de $R$. communis superou aquela obtida no tratamento com água destilada, indicando que o material exerce atração sobre os adultos da mosca-branca.

Os resultados de atratividade obtidos após 48 horas da pulverização (Tabela 1) revelaram que as plantas pulverizadas com extratos provenientes de folhas de M. pulegium, folhas e sementes de $A$. indica, ramos e folhas de $T$. pallida, sementes de $P$. nigrum e folhas
+ ramos de $M$. azedarach foram menos atrativas, diferindo das plantas pulverizadas com água destilada e com folhas de $C$. nardus e $C$. sativum, que atraíram maior número de indivíduos. Em trabalho semelhante, visando medir a atratividade de B. tabaci em plantas de feijoeiro tratadas com 27 extratos vegetais, Gómez et al. (1997) constataram significativa repelência nas plantas pulverizadas com extratos provenientes de $R$. graveolens, o que não foi confirmado no presente trabalho. Com relação ao controle de carunchos de feijão pelo uso de plantas inseticidas, Mazzonetto \& Vendramim (2003) notaram repelência à Acanthoscelides obtectus Say, quando misturaram grãos com pós provenientes de $R$. graveolens, M. pulegium, C. ambrosioides e E. citriodora.

No geral, observou-se que os tratamentos à base de folhas de A. indica $\mathrm{e}$ M. pulegium foram menos atrativos aos adultos da mosca-branca, podendo ser recomendados como alternativas para o controle do inseto. Deve-se ressaltar 
Tabela 2. Número médio ( \pm EP) de ovos $/ \mathrm{cm}^{2}$ de B. tabaci biótipo B contados em folíolos de tomateiro e índice de preferência para oviposição (IPO), obtidos 48 horas após a aplicação de diferentes extratos vegetais (average number $\left( \pm \mathrm{EP}\right.$ ) of eggs $/ \mathrm{cm}^{2}$ of $B$. tabaci biotype B, on tomato leaflets and, preference index of oviposition (IPO), obtained 48 hours after the application of various vegetable extracts). Botucatu, UNESP, 2006.

\begin{tabular}{|c|c|c|c|}
\hline \multirow{2}{*}{ Extrato $^{1}$} & \multirow{2}{*}{$\mathbf{N}^{\circ}$ de ovos ${ }^{2}$} & \multicolumn{2}{|c|}{ Preferência para oviposição3 } \\
\hline & & Índice ( EP) & Classificação \\
\hline Cymbopogon nardus (F) & $2,83 \pm 0,22 a$ & $28,34 \pm 12,41$ & Estimulante \\
\hline Trichilia pallida $(\mathrm{R})$ & $1,58 \pm 0,16 b$ & $0,00 \pm 12,41$ & Neutro \\
\hline Água destilada & $1,58 \pm 0,21 b$ & $0,00 \pm 12,41$ & Padrão \\
\hline Azadirachta indica (S) & $1,50 \pm 0,21 b$ & $-2,60 \pm 12,41$ & Neutro \\
\hline Eucalyptus citriodora (F) & $1,42 \pm 0,21 \mathrm{~b}$ & $-5,33 \pm 12,41$ & Neutro \\
\hline Coriandrum sativum $(F)$ & $1,33 \pm 0,13 b$ & $-8,59 \pm 12,41$ & Neutro \\
\hline Chenopodium ambrosioides $(F+R+I)$ & $1,25 \pm 0,21 b$ & $-11,66 \pm 12,41$ & Neutro \\
\hline Ruta graveolens $(F)$ & $1,25 \pm 0,06 \mathrm{bc}$ & $-11,66 \pm 12,41$ & Neutro \\
\hline Melia azedarach $(\mathrm{F}+\mathrm{R})$ & $1,16 \pm 0,16 b c$ & $-15,33 \pm 12,41$ & Deterrente \\
\hline Tajetes erecta $(F+R)$ & $1,08 \pm 0,16 b c$ & $-18,80 \pm 12,41$ & Deterrente \\
\hline Mentha pulegium $(F)$ & $1,00 \pm 0,19 b c$ & $-22,48 \pm 12,41$ & Deterrente \\
\hline Piper nigrum (S) & $0,91 \pm 0,16 \mathrm{bc}$ & $-26,91 \pm 12,41$ & Deterrente \\
\hline Trichilia pallida $(F)$ & $0,91 \pm 0,16 b c$ & $-26,91 \pm 12,41$ & Deterrente \\
\hline Azadirachta indica $(F)$ & $0,50 \pm 0,10 \mathrm{c}$ & $-51,92 \pm 12,41$ & Deterrente \\
\hline Ricinus communis $(F+R)$ & $0,50 \pm 0,10 \mathrm{c}$ & $-51,92 \pm 12,41$ & Deterrente \\
\hline $\mathrm{F}$ & $10,96^{*}$ & -- & -- \\
\hline CV (\%) & 9,24 & - & -- \\
\hline
\end{tabular}

${ }^{1}$ Legenda: $\mathrm{F}=$ folha; $\mathrm{R}=$ ramo; $\mathrm{I}=$ inflorescência; $\mathrm{S}=$ semente. ${ }^{2}$ Dados originais. Para análise estatística foram transformados em $(x+0,5)^{1 / 2}$. Médias seguidas de mesma letra, na coluna não diferem entre si pelo teste de Tukey a $5 \%$ de probabilidade. ${ }^{3} \mathrm{IPO}=[(\mathrm{T}-\mathrm{P}) /(\mathrm{T}+\mathrm{P})]$ x 100. IPO varia de +100 (muito estimulante) até -100 (total deterrência), sendo o valor 0 indicativo de neutralidade $\left({ }^{1} \mathrm{~F}=\right.$ leaf; $\mathrm{R}=$ branch; $\mathrm{I}=$ inflorescence; $\mathrm{S}=$ seed. ${ }^{2}$ Original data, transformed in $(x+0,5)^{1 / 2}$ for statistical analysis. Means followed by the same letter in the column did not differ from each other; Tukey, $5 \% .{ }^{3} \mathrm{IPO}=[(\mathrm{T}-\mathrm{P}) /(\mathrm{T}+\mathrm{P})] \mathrm{x} 100$. IPO varies from +100 (very stimulant) to -100 (total deterrence), where the value 0 indicate the neutrality).

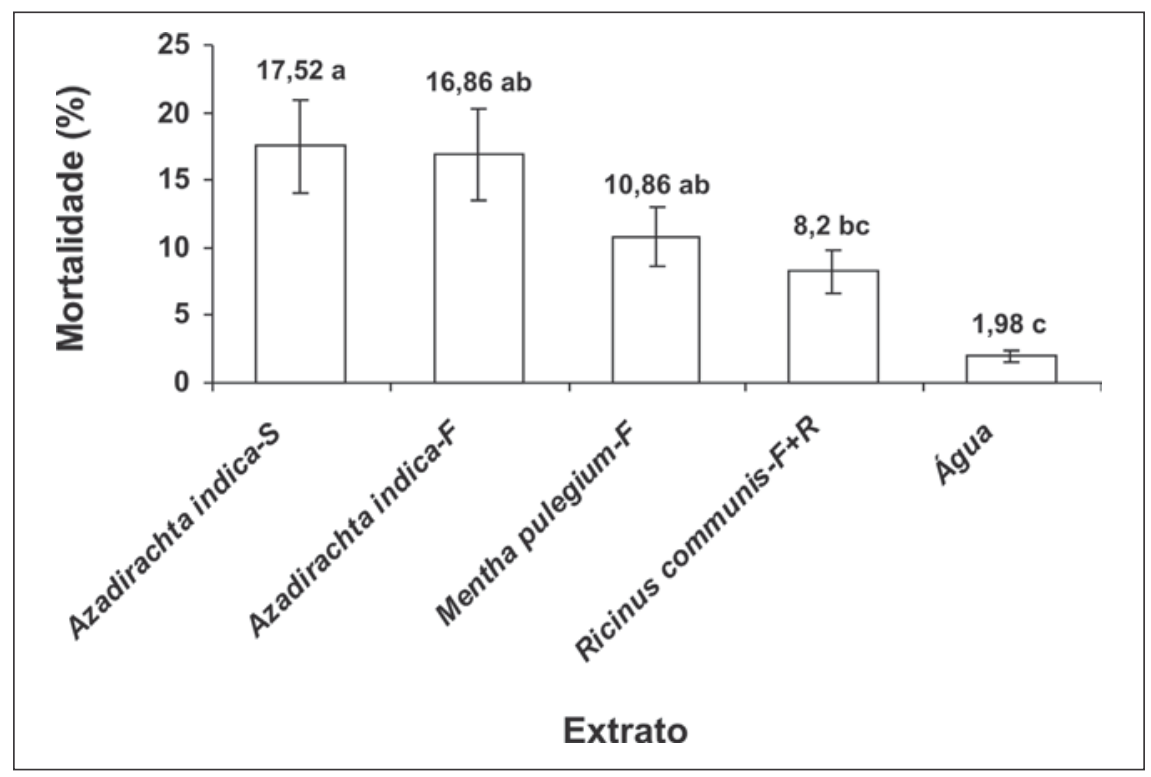

Figura 1. Mortalidade média ( $\pm \mathrm{EP}$ ) de ninfas de $B$. tabaci biótipo B em plantas de tomateiro irrigadas com diferentes extratos vegetais. Legenda: $\mathrm{F}=$ folha; $\mathrm{R}=$ ramo; $\mathrm{S}=$ semente. Médias seguidas de mesma letra, não diferem entre si pelo teste de Tukey (p d" 0,05 ) (average mortality $(( \pm \mathrm{EP})$ of $B$. tabaci biotype $\mathrm{B}$ on tomato plants irrigated with various vegetable extracts. Legend: $\mathrm{F}=$ leaf; $\mathrm{R}=$ branch; $\mathrm{S}=$ seed) (mcans followed by the same letter in the column did not differ from each other; Turkey, 5\%). Botucatu, UNESP, 2006. que, no caso específico da mosca-branca B. tabaci biótipo B em tomateiro, a baixa atratividade é de grande importância, uma vez que, evitando que o inseto chegue até a planta, evita-se também que ele se alimente e a contamine com geminivírus.

De acordo com Martinez (2002), os efeitos repelentes, inseticidas e/ou insetistáticos de extratos de sementes e folhas de $A$. indica contra pragas são promissores, sendo atualmente alvo de estudos em muitos centros de pesquisa entomológica no mundo.

Comparando-se o número médio de ovos da mosca-branca em plantas de tomateiro IAC-Santa Clara pulverizadas com diferentes extratos vegetais (Tabela 2), observa-se que a oviposição foi menor nos folíolos contendo extratos provenientes de folhas + ramos de $R$. communis e de folhas de A. indica, diferindo do tratamento à base de água destilada. $\mathrm{O}$ extrato de folhas de $C$. nardus destacou-se por aumentar a oviposição do inseto sobre os folíolos de tomateiro. O comportamento do inseto frente aos extratos de folhas + ramos de $R$. communis e de folhas de $A$. indica sugere que estes materiais apresentam compostos voláteis, deterrentes à oviposição de B. tabaci biótipo B, e que, segundo Lara (1991), impedem que o inseto continue a ovipositar num local devido à presença de fatores adversos. Os índices de preferência para oviposição classificaram os extratos à base de folhas + ramos de M. azedarach, folhas + ramos de $T$. erecta, folhas de M. pulegium, sementes de P. nigrum, folhas de T. pallida, folhas de A. indica e folhas + ramos de $R$. communis como deterrentes à oviposição do inseto, comparativamente à água destilada. Em função da elevada taxa de oviposição nos folíolos pulverizados com extrato de folhas de $C$. nardus, o índice classificou esse material como estimulante à oviposição de B. tabaci biótipo B, sendo, portanto, inadequado para a finalidade testada.

O período médio de desenvolvimento (ovo a adulto) da mosca-branca variou de 20,02 a 20,96 dias, não sendo detectada diferença entre os tratamen- 
tos, indicando que a aplicação dos extratos aquosos na dose testada por via sistêmica não afetou o desenvolvimento dos insetos confinados às plantas de tomateiro.

Analisando-se a mortalidade média de ninfas de B. tabaci biótipo B (Figura $1)$, observa-se que a presença dos extratos à base de sementes e folhas de $A$. indica e de folhas de M. pulegium afetou a sobrevivência das formas jovens do inseto, elevando os índices de mortalidade em 88,7, 88,3 e 81,8\%, respectivamente, em relação à mortalidade obtida com a água destilada. O efeito inseticida de extratos aquosos provenientes de plantas da família Meliaceae já havia sido relatado por Souza \& Vendramim (2001), que constataram índices de mortalidade ninfal dessa mosca-branca na ordem de 51,2 e $55,1 \%$, pela pulverização de extratos à base de frutos verdes de $M$. azedarach e ramos de $T$. pallida, respectivamente.

Os significativos índices de mortalidade de ninfas da mosca-branca obtidos pelo uso de extratos aquosos de sementes de $A$. indica via sistêmica (Figura 1) corroboram os resultados obtidos por Souza \& Vendramim (2005), que constataram mortalidades acima de $90 \%$ pelo uso desse material. Entretanto, no trabalho desses autores, as plantas de tomateiro foram irrigadas em sacos plásticos com capacidade para $300 \mathrm{~mL}$ de solo (substrato), enquanto que na presente pesquisa optou-se por utilizar vasos com 2 L de capacidade, o que pode justificar os índices de mortalidade inferiores aqui relatados.

Os resultados obtidos no trabalho indicam que a pulverização de extratos aquosos provenientes de partes vegetais de $M$. pulegium, A. indica, $M$. azedarach e T. pallida torna as plantas de tomateiro menos atrativas aos adultos de $B$. tabaci biótipo B. Constatou-se também que os extratos de $A$. indica e $R$. communis provocam redução na oviposição do inseto sobre os folíolos de tomateiro. Por fim, constatou-se que a aplicação de extratos aquosos de $A$. indica e $M$. pulegium via sistema radicular provoca significativa mortalidade de ninfas da mosca-branca, revelando bom potencial inseticida.
Devido à grande disponibilidade e facilidade de cultivo dessas espécies botânicas, o preparo e uso de extratos aquosos pode ser indicado como uma forma alternativa e viável para o controle da mosca-branca em tomateiro, especialmente para os pequenos produtores que exploram essa hortaliça. Aspectos relacionados à freqüência de emprego, bem como às concentrações mais adequadas, evitando riscos ao homem e também fitotoxicidade, requerem maiores estudos, devendo ser alvo de futuras pesquisas abordando o emprego de plantas inseticidas no controle de $B$. tabaci biótipo B em tomateiro.

\section{REFERÊNCIAS}

BALDIN ELL; TOSCANO LC; LIMA ACS; LARA FM; BOIÇA JR AL. 2000. Preferência para oviposição de Bemisia tabaci biótipo B por genótipos de Cucurbita moschata e Cucurbita maxima. Boletín de Sanidad Vegetal Plagas 26: 409-413.

BALDIN ELL; VENDRAMIM JD; LOURENÇÃO AL. 2005. Resistência de genótipos de tomateiro à mosca-branca Bemisia tabaci (Gennadius) biótipo B (Hemiptera: Aleyrodidae). Neotropical Entomology 34: 435-441.

BOGORNI PC; VENDRAMIM JD. 2005. Efeito subletal de extratos aquosos de Trichilia spp. sobre o desenvolvimento de Spodoptera frugiperda (J.E. Smith) (Lepidoptera: Noctuidae) em milho. Neotropical Entomology 34: 311-317.

CAMARGO FILHO WP. 2001. Perspectivas do mercado de tomate para indústria e mesa. Informações Econômicas 31: 51-54.

CARNEIRO JS; HAJI FNP; BLEICHER E; SILVA PHS; ALENCAR JA; ARAÚJO LHA; BARBOSA FR. 1999. Uma proposta de manejo - I. Granja 55: 124-125.

CUNHA US; VENDRAMIM JD; ROCHA WC; VIEIRA PC. 2005. Potencial de Trichilia pallida Swartz (Meliaceae) como fonte de substâncias com atividade inseticida sobre a traça-do-tomateiro, Tuta absoluta (Meyrick) (Lepidoptera: Gelechiidae). Neotropical Entomology 34: 667-673.

FARIA JC; SOUZA-DIAS JAC; SLACK SA; MAXWELL DP. 1997. A new geminivirus associated with tomato in the State of São Pau1o, Brazil. Plant Disease 81: 423.

FRANÇA FH; VILLAS BÔAS GL; CASTELO BRANCO MC; MEDEIROS MA. 2000. Manejo integrado de pragas. In: SILVA JBC; GIORDANO LB (eds). Tomate para processamento industrial. Brasília: Embrapa Informação Tecnológica/Embrapa Hortaliças. p. 112-127.
GALLO D; NAKANO O; SILVEIRA NETO S; CARVALHO RPL; BATISTA GC; BERTI FILHO E; PARRA JRP; ZUCCHI RA; ALVES SB; VENDRAMIM JD; MARCHINI LC; LOPES JRS; OMOTO C. 2002. Entomologia agrícola. Piracicaba: FEALQ. 920p.

GÓMEZ P; CUBILLO D; MORA GA; HILJE L. 1997. Evaluación de dpossibles repelentes de Bemisia tabaci: II. Extractos vegetables. Manejo Integrado de Plagas 46: 17-25.

LARA FM. Princípios de resistência de plantas a insetos. 1991. São Paulo: Ícone. 336p.

LOPES CA; ÁVILA AC; BEZERRA IC; CHARCHAR JM; QUEZADO-DUVAL AM. 2000. Doenças: identificação e controle. In: SILVA JBC; GIORDANO LB (eds). Tomate para processamento industrial. Brasília: Embrapa Informação Tecnológica/Embrapa Hortaliças. p. 88-111.

MARTINEZ SS (ed). 2002. O nim Azadirachta indica - natureza, usos múltiplos, produção. Londrina: IAPAR. 142p.

MATOS ES; SIQUEIRA WJ; LOURENÇÃO AL; MELOAMT; SAWASAKI HE; SOUZA-DIAS JAC; COLARICCIO A. 2003. Resistência de genótipos de tomateiro a um isolado de geminivírus do cinturão verde de Campinas, São Paulo. Fitopatologia Brasileira 28: 159-165.

MAZZONETTO F; VENDRAMIM JD. 2003. Efeito de pós de origem vegetal sobre Acanthoscelides obtectus (Say) (Coleoptera: Bruchidae) em feijão armazenado. Neotropical Entomology 32: 145-149.

OLIVEIRA MRV; SILVA OLR. 1997. Prevenção e controle da mosca-branca Bemisia argentifolii (Hemiptera: Aleyrodidae). Brasília: Ministério da Agricultura e do Abastecimento, Departamento de Defesa e Inspeção Vegetal. 16p. (Alerta Fitossanitário, 1).

POLSTON JE; ANDERSON PK. 1999. Surgimiento y distribución de geminivirus transmitidos por mosca blanca em tomate en el Hemisferio Occidental. Manejo Integrado de Plagas y Agroecología 53: 24-42.

PRABHAKER N; TOSCANO NC; COUDRIET DL. 1999. Comparison of neem, urea, and amitraz as oviposition supressants and larvicides against Bemisia argentifolii (Homoptera: Aleyrodidae). Journal of Economic Entomology 92: 40-46.

RAIJ B; CANTARELLA H; QUAGGIO JA; FURLAN AMC. 1997. Recomendações de adubação e calagem para o estado de São Paulo. Campinas: IAC. 285p. (Boletim Técnico 100).

SOUZA AP; VENDRAMIM JD. 2000. Atividade ovicida de extratos aquosos de meliáceas sobre a mosca-branca Bemisia tabaci (Gennadius) biótipo B em tomateiro. Scientia Agricola 72: 159-170.

SOUZA AP; VENDRAMIM JD. 2001. Atividade inseticida de extratos aquosos de meliáceas sobre a mosca-branca Bemisia tabaci (Genn.) biótipo B (Hemiptera: Aleyrodidae). Neotropical Entomology 30: 133-137.

SOUZA AP; VENDRAMIM JD. 2005. Efeito translaminar, sistêmico e de contato de extrato aquoso de sementes de nim sobre Bemisia tabaci (Genn.) biótipo B em tomateiro. Neotropical Entomology 34: 83-87.

VILLAS BÔAS GL; FRANÇA F; DE ÁVILA AC; BEZERRA IC. 1997. Manejo integrado da mosca-branca Bemisia argentifolii Bellows \& Perring (Homoptera: Aleyrodidae) no Distrito Federal. Brasília: EMBRAPA. 11p. (Circular Técnica, 9). 